\title{
Forecasting Prices in Financial Markets Using Artificial Neural Networks
}

\author{
Fernando Villada-Duque ${ }^{1}$, Jesús María López-Lezama² ${ }^{2}$ and Jorge Barrientos-Marín ${ }^{3}$ \\ ${ }^{1}$ Departamento de Ingeniería Eléctrica, Universidad de Antioquia Calle 70 No 52-21, Medellín 050010, Colombia. \\ ${ }^{2}$ Departamento de Ingeniería Eléctrica, Universidad de Antioquia Calle 70 No 52-21, Medellín 050010, Colombia. \\ ${ }^{3}$ Departamento de Economía, Universidad de Antioquia Calle 70 No 52-21, Medellín 050010, Colombia.
}

ORCIDs: 0000-0001-6577-2181 (Fernando), 0000-0002-2369-6173 (Jesús), 0000-0001-5368-1928 (Jorge)

\begin{abstract}
An Artificial Neural Network (ANN) model to forecast prices in financial markets is proposed in this work. The model is applied to two shares in the Colombian stock market and three commodities: gold price, oil price (West Texas Intermediate), and electricity price in the Colombian electricity market. Different neural networks configurations are trained using a series of prices of five to six months, where the first part is used as training patterns and the last month of data is left to test the predictive capabilities. The results show good performance of the neural networks with low training and testing errors.
\end{abstract}

Keywords: Financial markets, artificial neural networks, price forecasting.

\section{INTRODUCTION}

Financial markets are made up of the stock market, the foreign exchange market, the money market, the bond market, the credit market, the commodities market, and the derivatives market. They have been around the world for centuries since farmers would have needed to obtain seed for the next season planting, and perhaps to get food for their families [1]. These markets give the opportunity for speculating and hedging, being the options and futures, the main instruments of the derivative markets that are most appropriate for hedging.

For this reason, price discovery and price forecasting play an important role in financial markets, being most effective for risk management and giving the opportunity to make profits and hedge against unexpected events to traders. Reference [2] describes that despite their relative lack of liquidity, empirical evidence shows that traders prefer the options market, being leverage one of the main factors attracting to this market.

According to the preference for options, reference [3] studies their role when traded with stocks at the same time. By disaggregating price discovery in two components: the relative speed with which information is reflected in prices and noise, the authors found that actively-traded options listed on a sample of large U.S. stocks are the first to reflect new information approximately $25 \%$ of the time, indicating that they play an important role in price discovery.
Forecasting bubbles is also a very important issue in financial markets because every time the bubble burst, it causes financial turmoil and severe economic recession in all the markets. Trying to find early bubbles and reduce their impact, reference [4] finds warning mechanism of technical indicators applied to the stock market data of the United States, Japan, Germany, China, Brazil, and South Korea. It concludes that the proposed warning benchmarks can increase the accuracy of the bubble prediction, detecting the bubble in about six months before it burst in developed markets.

In the specialized literature, there are found several forecasting techniques applied to financial markets. There are two broad approaches: linear and non-linear models. Linear models consist of time series and dynamic programming methods while non-linear models consist of methods such as support vector machine, Markov chain, artificial neural networks (ANN), and stochastic distribution [5].

Reference [6] examined the predictive performance of the five of the above linear and non-linear models to forecast the stock market returns of selected indices from developed, emerging, and frontier markets, concluding that there is no single model that can be applied uniformly to all the markets.

Nevertheless, reference [7] found that artificial intelligence models such as ANN performed better than traditional models given the ability of this artificial intelligence technique to learn by training any complex input/output mapping that makes its use valuable and attractive from financial time series forecasting to travel recommendations systems [8].

Being electricity a very special commodity because of its economically non-storable characteristic and the need of a constant balance to keep the stability of the power system, it has encouraged researchers to intensify their efforts in the development of better forecasting techniques. A review of the methods for electricity price forecasting is shown in [9], aiming to explain the complexity of the available solutions, with a special emphasis on the strengths and weaknesses of the individual methods. The author also looks ahead and speculates on the directions the electricity price forecast should take in the future.

Trying the find the relationship among the returns of gold rates, crude oil prices and stocks included in Dow Jones 
Industrial Averages (DJIA), reference [10] examined a four year period data from 2016 to 2019 , concluding that DJIA and gold returns has a statistically significant relationship and has an impact on the oil price returns at $10 \%$ level of significance during the study period. Nevertheless, oil price returns and gold rates had no statistically significant relationship on the stock price returns.

The work done in our research group applying ANN to price forecasting in financial markets is shown in this paper. These applications include the gold market, the stock market, the electricity market, the oil market. The results confirm some of the relationships found in [10] and [11] show a successful performance of ANN in predicting prices in these high volatility markets.

\section{ARTIFICIAL NEURAL NETWORKS (ANN)}

ANN are very effective to handle complicated classification and pattern recognition problems. The distinguish features of ANN are that they are data-driven, non-linear, and selfadaptive, making them valuable and attractive for forecasting time series. Figure 1 shows the structure of a feed forward ANN with two hidden layers and one output layer, which is enough to generate arbitrary complex decision regions. The number of inputs is directly depending on the available information to be classified, while the output neurons are equal in number to the classes to be separated.

From the point of view of problem solving, ANN are different from conventional computers that use sequential algorithms, while ANN act like the human brain, processing information in parallel and being able to learn and generalize to situations not included in the training process. For this reason, ANN can process information faster than conventional computers, but they have the disadvantage of not being able to follow their response step by step as can be done when executing a conventional program on a computer, so it is not easy to detect errors.

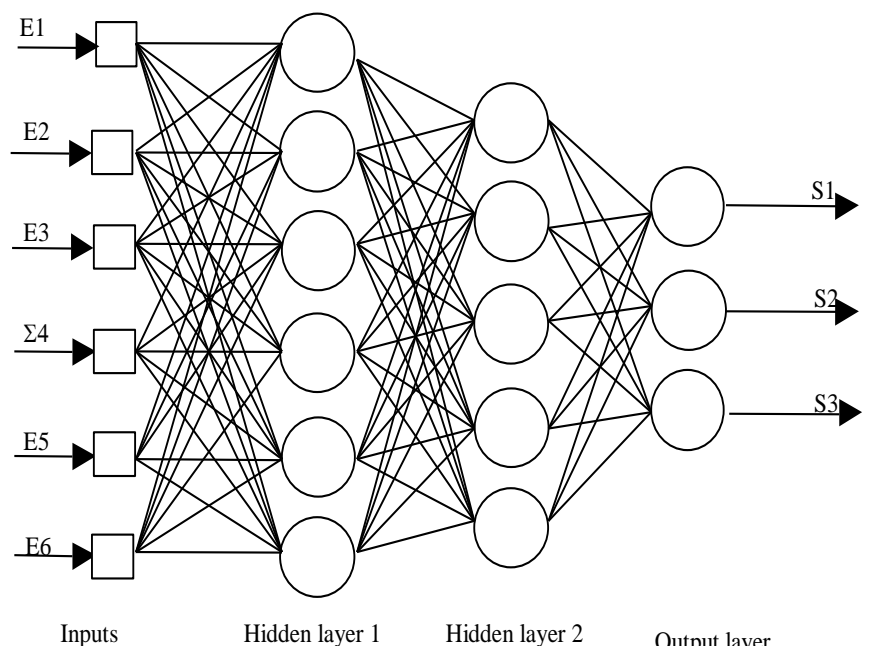

Fig 1. Feed forward neural network with two hidden layers
ANN have been applied to solve economic and financial problems, highlighting their application to time series forecasting and their ability to detect and exploit the nonlinearity in the data, even in conditions where there are incomplete data or the presence of noise. They algo stand out for their performance in solving complex problems, where the recognition of models or behaviours is important.

\section{METHODOLOGY}

The inputs for the forecasting model are based on the historical price series of gold, West Texas Intermediate (WTI) benchmark oil, electricity in the Colombian market, and two stocks listed in the Colombian stock exchange. The output of the model corresponds to the price to be predicted for the next day. In order to analyze the effect of the sentiment and risk aversion of investors, a second model was studied adding the price series of the dollar index (DXY) and the Standard and Poor's 500 index (S\&P500) to the inputs of the structures that forecast gold, oil, and stocks. For the case of electricity price forecast, a second model adds the average level of water reserves to the series of prices because of the dependence of this resource.

Different neural networks structures with one hidden layer and starting from the number of neurons equal to the average between the number of inputs and outputs, were tested in this work. Then, the number of neurons in said layer was gradually increased until the most recommended structure was obtained to forecast the price of the analyzed asset. The selection of the best ANN structure is carried out considering the following evaluation measures inside and outside the sample: RMSE (Root Mean Square Error) and MAPE (Mean Absolute Percentage Error), calculated using equations 1 and 2 .

$$
\begin{aligned}
& R M S E=\sqrt{\frac{1}{n} \sum_{t=1}^{n}\left(y_{t}^{\prime}-y_{t}\right)^{2}} \\
& M A P E=\frac{100}{n} \sum_{t=1}^{n}\left|\frac{y_{t}^{\prime}-y_{t}}{y_{t}}\right|
\end{aligned}
$$

Where, $n$ is the number of observations considered, $y_{t}$ is the real price, and $y_{t}^{\prime}$ is the price estimated by the model.

\section{TESTS AND RESULTS}

Table 1 shows performance of the best ANN structures found for each asset, using the first model, that is, including only the historical price series as training data. Table 2 shows the performance of the best ANN structures, which adds the series of water reserves (electricity price forecast) or the price series of DXY index and S\&P500 index (gold, oil and stock forecast) to inputs of the first model. 
International Journal of Engineering Research and Technology. ISSN 0974-3154, Volume 13, Number 11 (2020), pp. 3247-3250

(C) International Research Publication House. https://dx.doi.org/10.37624/IJERT/13.11.2020.3247-3250

Table 1. Performance of the best ANN structures with one input (price series)

\begin{tabular}{|l|c|c|c|c|}
\hline \multirow{2}{*}{ Type of asset } & \multicolumn{2}{|c|}{ With training data } & \multicolumn{2}{c|}{ Forecast } \\
\cline { 2 - 5 } & RMSE & MAPE & RMSE & MAPE \\
\hline Electricity price & 5.7460 & 0.5810 & 4.8614 & 0.4712 \\
\hline Gold price & 8.5738 & 0.5072 & 10.9454 & 0.6581 \\
\hline WTI oil price & 1.0563 & 0.8477 & 1.0461 & 0.8708 \\
\hline $\begin{array}{l}\text { Stock price } \\
\text { (asset 1) }\end{array}$ & 300.43 & 0.8116 & 462.33 & 1.2621 \\
\hline $\begin{array}{l}\text { Stock price } \\
\text { (asset 2) }\end{array}$ & 38.100 & 0.7770 & 69.190 & 1.4385 \\
\hline
\end{tabular}

Results of table 2 indicate a better performance of ANN structures following investor sentiment and their aversion to risk. These new structures include the historical asset price series, the price series of DXY index, and the price series of S\&P500 index to the ANN inputs for gold, oil and stock prices. The new structure for electricity price forecast includes the series of water reserves. The results confirm previous studies that indicate the risk aversion of world financial markets, and the dependence of hydraulic reserves in the Colombian electricity market.

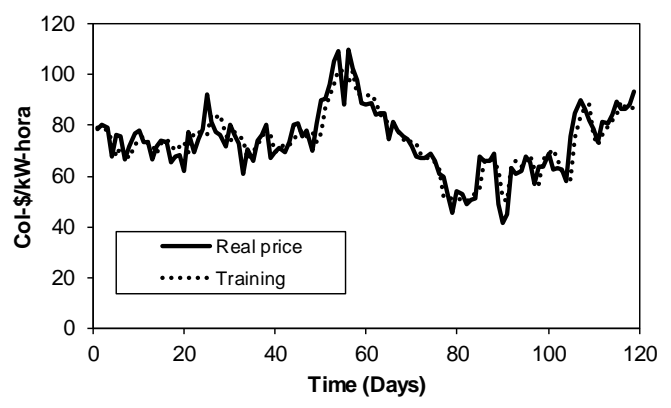

Fig. 2. Performance of electricity price with training data (inside the sample)

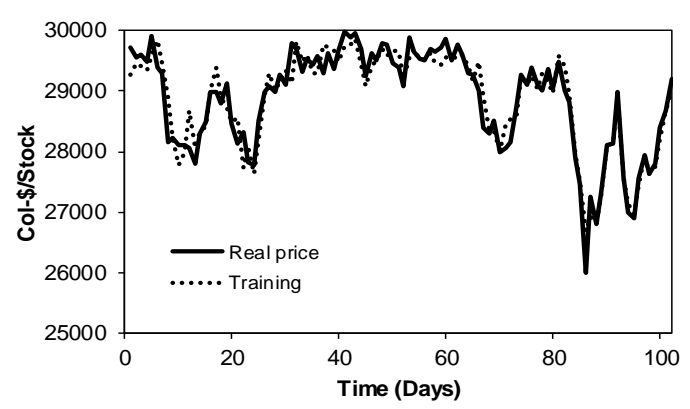

Fig. 4. Performance of stock 1 price with training data (inside the sample)
Table 2. Performance of the best ANN with price series and additional inputs*

\begin{tabular}{|l|c|c|c|c|}
\hline \multirow{2}{*}{ Type of asset } & \multicolumn{2}{|c|}{ With training data } & \multicolumn{2}{c|}{ Forecast } \\
\cline { 2 - 5 } & RMSE & MAPE & RMSE & MAPE \\
\hline Electricity price & 5.6149 & 0.5741 & 4.7699 & 0.4070 \\
\hline Gold price & 8.0579 & 0.4724 & 10.9715 & 0.6174 \\
\hline WTI oil price & 0.7579 & 0.5861 & 0.9617 & 0.7312 \\
\hline $\begin{array}{l}\text { Stock price } \\
\text { (asset 1) }\end{array}$ & 220.71 & 0.4820 & 420.42 & 1.2113 \\
\hline $\begin{array}{l}\text { Stock price } \\
\text { (asset 2) }\end{array}$ & 32.060 & 0.6406 & 74.830 & 1.4084 \\
\hline \multicolumn{5}{|c|}{ Average water reservoir level for electricity } \\
DXY index and S\&P500 index for other assets
\end{tabular}

Figures 2 and 3 show the performance of the best ANN structure inside the sample (training) and outside the sample (forecast) for the price of electricity in the Colombian electricity market. Figures 4 and 5 show the performance of the best ANN structure for one of the shares of the Colombian stock market. The forecasts are very close to reality in all the cases.

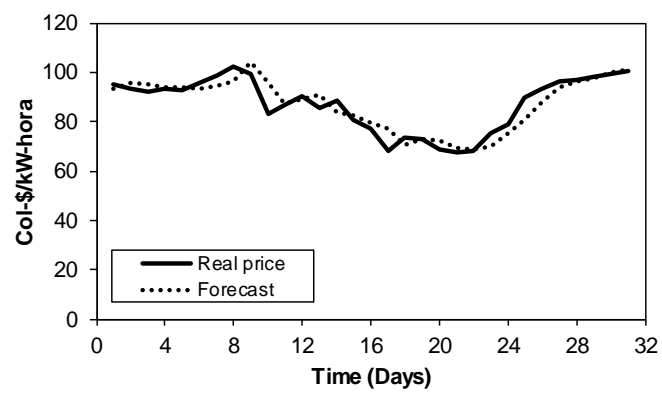

Fig. 3. Forecast of the electricity price (outside of the sample)

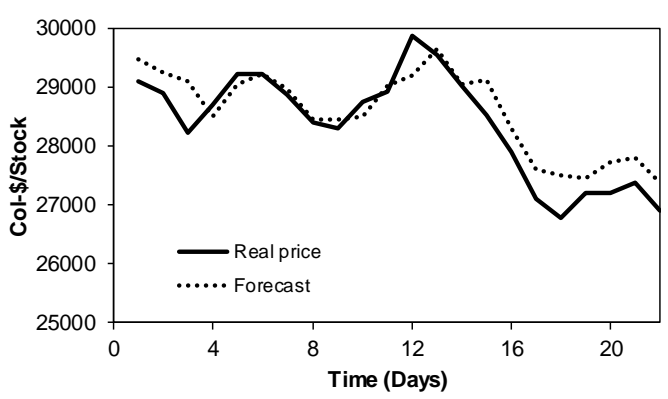

Fig. 5. Forecast of stock 1 price (outside the sample) 


\section{CONCLUSIONS}

This paper proposes a model for forecasting prices in financial markets using artificial neural networks. The model is applied to two shares in the Colombian stock market and three commodities: gold, WTI oil, and electricity. Two networks structures are used, including the daily price series in the first and the prices series plus other explanatory variables in the second. These explanatory variables are the level of water reserves for electricity prices, and the DXY index and S\&P500 index for the gold, oil, and stock prices.

There were found better results when including other explanatory variables in the second structure, achieving lower prediction errors. It confirms the effect of the level of water reservoirs in the Colombian electricity market, and the risk aversion of investors through the DXY and S\&p500 indices in the other assets studied.

\section{ACKNOWLEDGEMENTS}

The authors gratefully acknowledge the financial support provided by the Colombia Scientific Program within the framework of the call Ecosistema Científico (Contract No. FP44842- 218-2018). Likewise, Universidad de Antioquia (Colombia) is acknowledged for the financial support through the Sostenibilidad program.

\section{REFERENCES}

[1] M. Levinson, «Guide to Financial Markets». The Economist (2018).

[2] D. Easley, M. O’Hara, and P. Srinivas, «Option volumen and stock prices: evidence on where informed traders trade», J. Financ., 53 (1998), pp. 431-465.

[3] V. Patel, T. J. Putnins, D. Michayluk, and S. Foley, «Price discovery in sotck and options markets», Journal of Financial Markets, 47 (2020), pp. 1-28, doi: 10.1016/j.finmar.2019.100524.

[4] T. Chung-Hsiang and L. Szu-Lang, «Bubble prediction and comparative analysis of emerging and mature markets», International Research Journal of finance and Economics, 175 (2019), pp. 104-115.

[5] I. A. Samuel, T. M. Adeyemi-Kayode, A. A. Olajube, S. T. Oluwasijibomi, and A. I. Aderibigbe, «Artificial neural network and particle swarm optimization for medium term electrical load forecasting in a smart campus», International Journal of Engineering Research and Technology, vol 13, n. ${ }^{\circ} 6$ (2020), pp. 1273-1282.

[6] M. Mallikarjuna and R. P. Rao, «Evaluation of forecasting methods from selected stock market returns», Financ Innov, vol 5, no 40 (2019).

[7] X. Zhong and D. Enke, «Predicting the daily return direction of the stock market using hybrid machine learning algorithms», Financ Innov, vol 5, no 4 (2019), pp. 1-20.
[8] S. Bairavel and M. Krishnamurthy, «User preference and reviews analysis with neural networks for travel recommender systems», International Journal of Engineering Research and Technology, vol 13, n. ${ }^{\circ} 8$ (2020), pp. 1896-1900.

[9] R. Weron, «Electricity price forecasting: A review of the state-of-the-art with a look into the future», International Journal of Forecasting, 30 (2014), pp. 1030-1081.

[10] E. Rengasamy, «A study on the relationship among the returns of gold rates, crude oil prices and the stock market investments! An empirical evidence!!», International Research Journal of Finance and Economics, 180 (2020), pp. 27-39.

[11] J. Barrientos-Marín, E. Tabares-Orozco and E. Velilla, «Forecasting Electricity Price in Colombia: A Comparison Between Neural Network, ARMA Process and Hybrid Models », International Journal of Energy Economics and Policy, vol 8, n. ${ }^{\circ} 3$ (2018), pp. 97-106 